\begin{tabular}{|c|c|}
\hline Title & Recrystallization of cold rolled oxide dispersion strengthened copper during room temperature annealing \\
\hline Author(s) & Aghamiri, S. M. S.; Ukai, S.; Oono, N.; Kasada, R.; Noto, H.; Hishinuma, Y.; Muroga, T. \\
\hline Citation & $\begin{array}{l}\text { Journal of alloys and compounds, } 798,187-193 \\
\text { https://doi.org/10.1016/.jallcom.2019.05.248 }\end{array}$ \\
\hline Issue Date & $2019-08-25$ \\
\hline DOC URL & http:/hdl.handle.net/2115/82518 \\
\hline Rights & $\begin{array}{l}\text { (9 2019. This manuscript version is made available under the CC-BY -NC-ND } 4.0 \text { license } \\
\text { http://reativecommons.org/icenses/by-nc-nd/4.0/ }\end{array}$ \\
\hline Rights(URL) & http://creativecommons.org/icenses/by-nc-nd/4.0/ \\
\hline Type & article (author version) \\
\hline File Information & 1-s2.0-s0925838819319309-main.pdf \\
\hline
\end{tabular}

Instructions for use 


\section{Accepted Manuscript}

Recrystallization of cold rolled oxide dispersion strengthened copper during room temperature annealing

S.M.S. Aghamiri, S. Ukai, N. Oono, R. Kasada, H. Noto, Y. Hishinuma, T. Muroga

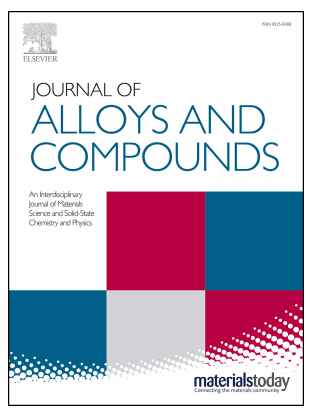

PII:

S0925-8388(19)31930-9

DOI:

https://doi.org/10.1016/j.jallcom.2019.05.248

Reference: JALCOM 50780

To appear in: Journal of Alloys and Compounds

Received Date: 19 February 2019

Revised Date: 10 May 2019

Accepted Date: 21 May 2019

Please cite this article as: S.M.S. Aghamiri, S. Ukai, N. Oono, R. Kasada, H. Noto, Y. Hishinuma, T. Muroga, Recrystallization of cold rolled oxide dispersion strengthened copper during room temperature annealing, Journal of Alloys and Compounds (2019), doi: https://doi.org/10.1016/j.jallcom.2019.05.248.

This is a PDF file of an unedited manuscript that has been accepted for publication. As a service to our customers we are providing this early version of the manuscript. The manuscript will undergo copyediting, typesetting, and review of the resulting proof before it is published in its final form. Please note that during the production process errors may be discovered which could affect the content, and all legal disclaimers that apply to the journal pertain. 


\title{
Recrystallization of cold rolled oxide dispersion strengthened copper during room temperature annealing
}

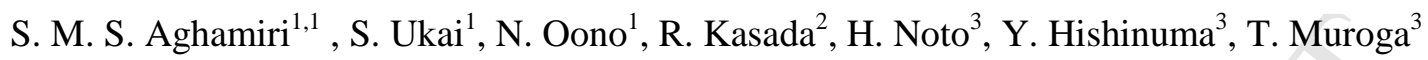 \\ ${ }^{I}$ Graduate School of Engineering, Hokkaido University, Sappor 060-8628, Japan \\ ${ }^{2}$ Institute of Materials Research, Tohoku University, sendai 980-8577, Japan \\ ${ }^{3}$ National Institute of Fusion Science, Gifu 509-5202, Japan
}

\begin{abstract}
Static discontinuous recrystallization was studied during room temperature annealing of a newly designed $80 \%$ room temperature rolled oxide dispersion strengthened copper. At early stages of annealing, fine new oriented nanosized/submicron grains were recrystallized in the unique matrix of single brassoriented deformed grain. Upon longer annealing time up to 14 months, the size, area fraction and number density of the recrystallized grains increased significantly along with changing the crystallographic textures. The analysis of misorientation angle distribution of boundaries indicated transformation of low angle boundaries to high angle boundaries results in nucleation of recrystallized grains by significant contribution of static recovery. Furthermore, the constant level of mechanical hardness after recrystallization was interpreted by the balance between grain size hardening, oxide particle hardening and strain hardening.
\end{abstract}

Keywords: Static discontinuous recrystallization; grain boundary; texture; Mechanical strength; Misorientation angle distribution

\footnotetext{
${ }^{1}$ Corresponding author. Hokkaido University, Sappor 060-8628, Japan.

Email Address: sms.aghamiri@gmail.com
} 


\section{Introduction}

Oxide dispersion strengthened (ODS) copper alloys are new category of developing energy materials possessing good mechanical properties and expecting irradiation resistance [1-5]. The distribution of fine oxide particles is the key feature of these materials for controlling the microstructure during processing and service. Generally, recrystallization of ODS alloys has been observed to be affected seriously by fine dispersion of oxide particle and retarded to high temperatures near melting point of the alloy [6,7]. Though previous studies arguing the recrystallization of copper start in a low temperature of $\sim 0.3 \mathrm{~T}_{\mathrm{m}}$ lower than other metals $[8,9]$, recent reports show that copper can recrystallize even at room temperature $\left(\sim 0.2 \mathrm{~T}_{\mathrm{m}}\right)[10,11]$.

In order to reach optimum balance of strength and ductility, various studies have recently performed to understand the microstructure of copper and copper alloys during/after rolling [10-17]. New results of Konkova et al. [12] indicate that static recrystallization can happen in cryo-rolled pure copper during long time ( 1.5 years) storage at room temperature as a result of both grain-boundary bulging and recovery. At low temperatures, recovery is generally believed to compete with recrystallization and it has expected to play a substantial role at room-temperature. In another study [14], microstructural stability was observed in severely cryodeformed copper during long-term static storage at room temperature resulted in inhomogeneous grain growth. The high concentration of defects (i.e. vacancies) in the cryodeformed copper has been introduced as the reason of static recrystallization which significantly enhances grain-boundary mobility [11]. Although different studies have demonstrated possibility of 
recrystallization at room temperature after cryogenic rolled pure copper, there is no evidence of recrystallization after room temperature deformation. This subject is more attractive when a fine distribution of oxide particles as the barrier of grain boundary migration is dispersed in the microstructure. Hence, following to our new finding of a single brass-oriented deformed grain after room temperature rolling of ODS copper which deformed by partial slip mechanism [16], studying the recrystallization of such specific structure in view of the literature is a matter of particular importance. Such a modern microstructural investigation by the application of electron backscatter diffraction (EBSD) analyses via crystallographic texture and subgrain boundary and grain orientation spread have been introduced as the effective indications to partition the recrystallized/deformed structures [12]. Therefore, the objective of the present work is to evaluate the static recrystallization of ODS copper during long time annealing at room temperature and understanding the underlying mechanisms by advanced characterization techniques.

\section{Experimental}

In this study, $80 \%$ cold rolled ODS copper with a nominal composition of $\mathrm{Cu}-0.5 \mathrm{wt} \% \quad \mathrm{Y}_{2} \mathrm{O}_{3}$ was prepared by using high energy milling and subsequent sintering and final cold rolling at room temperature. The details of processing can be found elsewhere [16]. The $80 \%$ rolled ODS copper was stored at room temperature and investigated after two annealing time of one week and $\sim 14$ months.

The samples were analyzed by EBSD equipment attached to a field emission scanning electron microscope (JEOL JSM-6500F) operating at 15 $\mathrm{kV}$ with a step size of as low as $20 \mathrm{~nm}$. The observations were made on the 
rolling plane containing RD-TD directions. Sample preparation for EBSD was done by grinding with SiC paper up to 2000 grit and then polishing with $1 \mu \mathrm{m}$ diamond paste and final polishing with Struers colloidal silica suspension. To attain EBSD data, TSL-OIM analysis software was used for different data analyses. To minimize measurement errors, the grains were dilated to minimum 3 pixels before data analysis. The orientation imaging map (OIM) was used based on inverse pole figure to study the orientation of deformed and recrystallized grains. The grain boundaries map (GBM) was analyzed to distinguish high angle boundaries (HABs) $\left(\geq 15^{\circ}\right)$ and low angle boundaries $(\mathrm{LABs})\left(<15^{\circ}\right)$. To partition the recrystallized grains from the deformed matrix, grain orientation spread (GOS) analysis was used to measure variations of crystallographic orientation within the grains. The GOS within each grain bordered by HAB was determined by calculating the average deviation between the orientation of each pixel in the grain and the average orientation for that grain. The grains having a GOS value less than $\sim 2^{\circ}$ are defined as recrystallized ones [12,18]. The orientation distribution function (ODF) at $\varphi_{2}=0^{\circ}, 45^{\circ}, 65^{\circ}$ was studied to specify the texture of deformed and recrystallized microstructures. The average grain size measurements were performed based on the number fraction assuming each grain as a circle. To clarify the change of grain boundaries misorientation during recrystallization, the misorientation angle distribution was evaluated. A $200 \mathrm{kV}$-JEOL JEM-2010 transmission electron microscope (TEM) was used to study the microstructures in high magnification. The thin foil for TEM observation was prepared by focused ion beam (FIB) (JEOL JIB-4600F) and the thinning was accomplished up to the thickness of $\sim 100 \mathrm{~nm}$. To evaluate the change of mechanical strength, Vickers microhardness data of the rolled and annealed samples were 
obtained by a HMV-Micro Hardness Tester-SHIMADZU, under a load of $980 \mathrm{mN}$ and dwell time of $30 \mathrm{~s}$ with 10 times measurements. The values of average mechanical strength were reported, and the maximum and minimum values were shown as error bar.

\section{Results}

\subsection{Microstructure evolution}

Fig.1 presents the EBSD analyses in a high magnification including OIM, GBM and GOS of the $80 \%$ cold rolled ODS copper after annealing for one week (a-c) and 14 months (d-f) at room temperature. OIM image (Fig. 1(a)) demonstrates very fine nano/submicron sized grains were nucleated with new orientations in the green matrix of rolled sample. These new grains can be realized in the GBM (Fig. 1(b)) bordered by HABs of higher than $15^{\circ}$ specified in blue color in the highly deformed matrix of LABs including boundaries of red color $\left(2^{\circ}-5^{\circ}\right)$ and green color $\left(5^{\circ}-15^{\circ}\right)$. The microstructural evolution of matrix including a high density of LABs during $80 \%$ cold rolling was explained in detailed previously with some aspects of related deformation mechanism in Ref. [16]. However, the GOS analysis (Fig. 1(c)) determines all of these new grains have a typical orientation spread value of less than $1^{\circ}$ as the bright recrystallized grains in the darker large deformed grain with a GOS value of $2.15^{\circ}$. After long time annealing of 14 months at room temperature, the EBSD analyses show a sharp microstructural evolution in the $80 \%$ cold rolled ODS copper. In compared to the short annealing time, the recrystallized grains can be distinguished by new orientations in different colors (Fig. 1(d)) and borders of HABs in blue color (Fig. 1(e)). In some cases, the new oriented grains are either with partial or complete LABs as shown by arrows. All of these 
new grains show lower GOS value of less than $2^{\circ}$ in brighter contrast (Fig. 1(f)) than dark contrast of deformed matrix including distribution of LABs substructures. The partitioning of recrystallized grains based on GOS value higher than $2^{\circ}$ indicates the recrystallized area fraction have increased from $2.3 \%$ with an average grain size of $57 \mathrm{~nm}$ in one-week annealed condition to $19.5 \%$ area fraction with larger grain size of $280 \mathrm{~nm}$ after long annealing time of 14 months. Furthermore, examination of number density of recrystallized grains in the same scanned area $\left(14.5 \times 42.6 \mu \mathrm{m}^{2}\right)$ with a step size of $80 \mathrm{~nm}$ demonstrates that the early 409 grains enhanced considerably to 1755 grains excluding the edge grains.

In order to understand the evolution of boundaries during recrystallization of ODS copper, misorientation angle distribution was examined during room temperature annealing in Fig. 2. As shown in the Fig. 2(a), at start of annealing, the deformed phase includes almost a total LABs $<10^{\circ}$ with the main misorientations in the range of $2-5^{\circ}$ of $72 \%$ number fraction. In contrast in Fig. 2(b), after long time room temperature annealing, the annealed structure shows a lower fraction of LABs and a portion of HABs mainly between $50-60^{\circ}$. According to the results, the evolution of misorientation angle distribution of boundaries after room temperature annealing for 14 months has been illustrated quantitatively in Fig. 2(c). The $97 \%$ LABs of less than $15^{\circ}$ reduced to $81 \%$ while HABs of higher than $15^{\circ}$ increased from $3 \%$ to $19 \%$ after long time room temperature annealing. Therefore, it clearly suggests the process of static discontinuous recrystallization was associated with transformation of LABs to HABs. Such a change in misorientation angle distribution of boundaries in room temperature is of particular interest and is not reported yet. 
Analysis of the annealed microstructure by bright-field TEM has been evaluated in Fig. 3. The cell band deformed structure can be still observed clearly in the rolling direction including dislocation boundaries in Fig. 3(a). It is evident some part of these cell structures has been depleted from the dislocations and some subgrains (grains) with a submicron sized indicated by red lines have been formed inside these cell bands with almost homogenous contrast. Analysis of other recrystallized grains in Fig. 3 (b) confirmed two neighboring grains which shows a high distribution of $\mathrm{Y}_{2} \mathrm{O}_{3}$ oxide particles in the lower one with surrounding deformed matrix of high dislocation density. This observation suggests formation of the recrystallized grains in the room temperature against the pinning force of oxide particles reported for metallic alloys in different references [10,11].

The grain orientations by texture analysis have been studied widely for fcc structure metals and the ideal rolling and recrystallized phases have been identified in the literature $[10,12,13]$. The ODS copper material studied in this work after 14 months annealing at room temperature was partitioned by GOS analysis into recrystallized and deformed phases and the ODF at $\varphi_{2}=0^{\circ}, 45^{\circ}, 65^{\circ}$ for each phase was evaluated in Fig. 4 . The deformed phase (Fig. 4(a)) expresses a high intensity ( 186 times than random) rolled texture near Brass orientation with an orientation of $\{441\}\langle 2 \overline{3} 4\rangle$. In previous study [16], the rolled texture just after deformation showed to be in exact Brass orientation $(\{011\}\langle 2 \overline{1} 1\rangle)$. This deviation might be explained based on the static recovery happening during room temperature annealing in the copper microstructure which has been reported during storage at room temperature [12]. In compared to deformed 
phase, the recrystallized phase (Fig. 4(b)) shows significant evolution in the crystallographic texture and it expands to a wide range of orientations with a lower max. intensity of 35 than random. The main orientations are belonged to $\{221\}\langle 1 \overline{2} 2\rangle$ with a high intensity of 25.6 times than random and $S$ orientation with intensity of 18.6 times than random in $\varphi_{2}=45^{\circ}$ and $65^{\circ}$, respectively. Other orientations are Goss $(\{011\}\langle 100\rangle) \times 6.6$, $\{034\}\langle 9 \overline{4} 3\rangle \times 7.1$ and $\mathrm{P}(\{011\}\langle 1 \overline{2} 2\rangle) \times 3.9$ and copper $(\{112\}\langle 111\rangle) \times$ 6.8. Formation of both $\{221\}\langle 1 \overline{2} 2\rangle$ and $\{034\}\langle 9 \overline{4} 3\rangle$ near to orientation of deformed texture indicates originating the main recrystallized grains from the crystallographic orientation of the deformed grains. In the ODS copper material, evolution of copper and $\mathrm{S}$ textures as the recrystallized textures are in contrast to as the deformed textures in pure copper. These textures are consistent with the same recrystallized texture of ODS copper after high temperature annealing around $\sim 800^{\circ} \mathrm{C}[16]$.

\subsection{Mechanical hardness}

Fig. 5 shows the comparison of mechanical hardness of ODS copper after $80 \%$ cold rolling and then 14 months annealing at room temperature. The mechanical hardness can be correlated with Vickers microhardness $\left(\mathrm{HV}_{0,1}\right)$ using the relationship provided by Tabor [19]:

$\sigma=1 / 3 H V_{0.1}$

As seen, the $80 \%$ cold rolled ODS copper bears a strength value of $559 \mathrm{MPa}$ and after 14 months annealing at room temperature, the strength value does not change. This constancy of hardness is in contrast to usual decrease in mechanical hardness during recrystallization and can be interpreted by the balance between grain size hardening $\left(\sigma_{G S}\right)$, oxide 
particle hardening $\left(\sigma_{O P}\right)$ and strain hardening $\left(\sigma_{S t}\right)$ during slow annealing at room temperature. By assumption of no grain size effect in the primary millimeter sized single deformed grain, grain size hardening can be estimated based on the Hall-Petch relation in the following relation [20]:

$$
\sigma_{G S}=K_{H P}\left(f d_{1}^{-1 / 2}+(1-f) d_{2}^{-1 / 2}\right)
$$

where $\mathrm{K}_{\mathrm{HP}}$ as Hall-Petch constant (4.5 MPa. $\mathrm{mm}^{1 / 2}$ ), $\mathrm{d}_{1}$ is the average grain size of recrystallized part $(0.28 \mu \mathrm{m})$ and $\mathrm{d}_{2}$ is the grain size of unrecrystallized part $(25.24 \mu \mathrm{m})$ and $f$ as the fraction of recrystallized part which is $\sim 0.2$ according to EBSD data in Fig. 2 (a). Hence, $\sigma_{G S}$ is calculated to be around $76 \mathrm{MPa}$. In addition, the moving dislocations inside the recrystallized grains can interact with fine oxide particles due to Orowan mechanism in contrast to saturated dislocation density in deformed matrix according to following relation [21]:

$\sigma_{O P}=f .0 .84 \frac{M G b}{2 \pi r \sqrt{1-v}\left(\sqrt{3 \pi / 2 f_{O P}}-\pi / 4\right)} \ln \left(\frac{\pi r}{4 b}\right)$

where $f$ as the fraction of recrystallized part ( 0.2), $M$ is Taylor factor (3), $\mathrm{G}$ is shear modulus $(44.7 \mathrm{GPa}), \mathrm{b}$ is burgers vector $(0.255 \mathrm{~nm}), v$ is Poisson's ratio (0.34), $\mathrm{r}$ and $\mathrm{f}_{\mathrm{OP}}$ are average radius and fraction of oxide particles, respectively $(\sim 5.4 \mathrm{~nm}$ and 0.0075 based on TEM studies supposing no change in oxide distribution during rolling). Accordingly, $\sigma_{O P}$ is calculated to be $\sim 23.4 \mathrm{MPa}$. In other side, the change in strain hardening based on releasing of dislocation accumulation in recrystallized part can be estimated by following relation [20]:

$\sigma_{S t}=f . \alpha M G b \rho^{1 / 2}$

where $f$ as the fraction of recrystallized part $(\sim 0.2), \alpha$ is a constant $(\sim 0.5)$, $\mathrm{M}$ as Taylor factor $(\sim 3), \mathrm{G}$ is shear modulus (44.7 GPa), $\mathrm{b}$ is Burgers vector 
$(0.255 \mathrm{~nm})$ and $\rho$ is dislocation density (estimated about $10^{15}$ from XRD analysis). Therefore, $\sigma_{S t}$ is calculated to be $\sim 108 \mathrm{MPa}$ which shows a comparable value with sum of $\sigma_{G S}$ and $\sigma_{O P}(\sim 99.4 \mathrm{MPa})$.

\section{Discussion}

To discuss about the static discontinuous recrystallization associated with transformation of LABs to HABs during room temperature annealing in $80 \%$ rolled ODS copper, two hypotheses can be considered: first, it can be supposed that recrystallization nuclei was originated from the subgrains as observed in Fig. 3 by the migration of LAB which was resulted in boundaries of higher misoriented angles. Although generally the migration of LABs can happen during recovery [22,23], considering activation energy near to the lattice self-diffusion of copper $\sim 49 \mathrm{kcal} / \mathrm{mole}$ [24] leads to very low mobility of LABs. The second hypothesis can be regarded as changing of primary subgrains by transforming the high misoriented LABs to HABs during recovery of free dislocations. The primary recrystallized nuclei after one-week annealing in Fig. 1(b) located mainly around the green boundary (5-15 ) and different TEM observations showing arrangement of dislocations around the recrystallized grain boundary (e.g. Fig. 3(a,b)) suggests that the latter case is more probable. However, in both cases the primary subgrains can be regards as the primary nucleation sites as confirmed by the main recrystallized texture $(\{221\}\langle 1 \overline{2} 2\rangle)$ near to the orientation of deformed microstructure (Fig. 4). Furthermore, the static recovery has a significant contribution especially in early stages for nucleation during the static discontinuous recrystallization. Another important observation around the recrystallized grains is formation of 
bulged high angle boundaries as indicated in high magnification inset image in Fig. 1(d). This finding suggests that the grain boundary bulging [10] is another phenomenon for progress of recrystallization during roomtemperature annealing of $80 \%$ rolled ODS copper. Accordingly, it is believed that the recrystallization nucleation resulted in high angle boundaries is provided by recovery process and then supported by straininduced grain boundary migration by formation of local bulging. This is in consistent with the case of cryogenically rolled copper [12] suggesting significant influence of grain boundary bulging and recovery during roomtemperature annealing.

\section{Conclusions}

In summary, the single-crystal like cold rolled ODS copper structure formed after $80 \%$ room temperature rolling has been found to recrystallize during room temperature annealing. Static discontinuous recrystallization was happened by formation of new textured recrystallized grains which their size, fraction and number density increased during long ( 14 months) annealing time. The constant level of strength/hardness after recrystallization was attributed to balance between grain size hardening and oxide particle hardening and strain hardening. The change in misorientation angle distribution of boundaries proved that transformation of LABs to HABs results in nucleation of recrystallized grains and static recovery has a significant role during evolution of boundaries.

\section{Acknowledgement}

The authors acknowledge the support by Grant-in-Aid for Scientific Research(A), 16H02443, Japan Society for the Promotion of Science. 


\section{References}

1. M. Li, S. J. Zinkle, Physical and mechanical properties of copper and copper alloys, in: R.M.J. Konings (Eds.), Comprehensive Nuclear Materials, Vol. 4, Elsevier Ltd., 2012, pp.667-690.

2. G. Carro, A. Muñoz, M.A. Monge, B. Savoini, R. Pareja, C. Ballesteros, P. Adeva, Fabrication and characterization of $\mathrm{Y}_{2} \mathrm{O}_{3}$ dispersion strengthened copper alloys, J. Nucl. Mater. 455 (2014) 655-659.

3. H. Zhuo, J. Tang, N. Ye, A novel approach for strengthening $\mathrm{Cu}-\mathrm{Y}_{2} \mathrm{O}_{3}$ composites by in situ reaction at liquidus temperature, Mater. Sci Eng. A 584 (2013) 1-6.

4. M.-N. Avettand-Fènoël, A. Simar, R. Shabadi, R. Taillard, B. de Meester, Characterization of oxide dispersion strengthened copper based materials developed by friction stir processing, Mater. Des. 60 (2014) 343-357.

5. B. Huang, Y. Hishinuma, H. Noto, T. Muroga, Mechanochemical processing of CuY2O3 alloy by MA-HIP for heat sink materials application, Fusion Eng. Des. 140 (2019) 33-40.

6. S. Ukai, Oxide Dispersion Strengthened Steels, in: R.M.J. Konings (Eds.), Comprehensive Nuclear Materials, Vol. 4, Elsevier Ltd., 2012, pp. 241-271.

7. S. H. Kim, D. N. Lee, Recrystallization of alumina dispersion strengthened copper strips, Mater. Sci Eng. A 313 (2001) 24-33.

8. W. Blum, Y.J. Li, K. Durst, Stability of ultrafine-grained Cu to subgrain coarsening and recrystallization in annealing and deformation at elevated temperatures, Acta Mater. 57 (2009) 5207-5217.

9. C.H.J. Davies, W.Q. Cao, C.F. Gu, R.Y. Lapovok, E.V. Pareloma, Texture and boundary characteristics of severely deformed and recrystallized copper, Mater. Sci. Forum 558-559 (2007) 177-182.

10. T. Konkova, S. Mironov, A. Korznikov, S.L. Semiatin, Microstructural response of pure copper to cryogenic rolling, Acta Mater. 58 (2010) 5262-5273.

11. HD. Meingelberg, M. Meixner, K. Lucke, The kinetics of the recrystallization of copper deformed at low temperatures, Acta Metall. 13 (1965) 835-844.

12. T. Konkova, S. Mironov, A. Korznikov, S.L. Semiatin, On the room-temperature annealing of cryogenically rolled copper, Mater. Sci. Eng. A 528 (2011) 7432-7443.

13. T. Konkova, S. Mironov, A. Korznikov, M.M. Myshlyaev, S.L. Semiatin, Annealing behavior of cryogenically-rolled copper, Mater. Sci. Eng. A 585 (2013) 178-189.

14. T. Konkova, S. Mironov, A. Korznikov and S.L. Semiatin, Microstructure instability in cryogenically deformed copper, Scripta Materialia 63 (2010) 921-924.

15. C.F. Gu, L.S. Toth, Y.D. Zhang and M. Hoffman, Unexpected brass-type texture in rolling of ultrafine-grained copper, Scr. Mater. 92 (2014) 51-54.

16. S. M. S. Aghamiri, N. Oono, S. Ukai, R. Kasada, H. Noto, Y. Hishinuma, T. Muroga, Brass-texture induced grain structure evolution in room temperature rolled ODS copper, Mater. Sci. Eng. A, 749 (2019) 118-128.

17. R. Ihira, H. Gwon, R. Kasada, S. Konishi, Improvement of tensile properties of pure $\mathrm{Cu}$ and $\mathrm{CuCrZr}$ alloy by cryo-rolling process, Fusion Eng. Design 109-111 (2016) 485-488.

18. D.P. Field, L.T. Bradford, M.M. Nowell, T.M. Lillo, The role of annealing twins 
during recrystallization of $\mathrm{Cu}$, Acta Mater. 55 (2007) 4233-4241.

19. S. Ukai, S. Ohtsuka, T. Kaito, H. Sakasegawa, N. Chikata, S. Hayashi, S. Ohnuki, High-temperature strength characterization of advanced 9Cr-ODS ferritic steels, Mater. Sci. Eng. A 510-511 (2009) 115-120.

20. S. M. S. Aghamiri, N. Oono, S. Ukai, R. Kasada, H. Noto, Y. Hishinuma, T. Muroga, Microstructure development and high tensile properties of $\mathrm{He} / \mathrm{H} 2$ milled oxide dispersion strengthened copper, J. alloys compd. 783 (2019) 674-679.

21. S. M. S. Aghamiri, N. Oono, S. Ukai, R. Kasada, H. Noto, Y. Hishinuma, T. Muroga, Microstructure and mechanical properties of mechanically alloyed ODS copper alloy for fusion material application, Nucl. Mater. Energy 15 (2018) 17-22.

22. F. J. Humphreys, M. Hatherly, Recrystallization and related annealing phenomena, Second Edition, Elsevier, UK, 2004.

23. M. Winning, A.D. Rollett, G. Gottstein, D.J. Srolovitz, A. Lim and L.S. Shvindlerman, Mobility of low-angle grain boundaries in pure metals, Phil. Mag. 90, (2010) 3107-3128.

24. R. Viswanathan and C. L. Bauer, Kinetics of grain boundary migration in copper bicrystals with [001] rotation axes, Acta Metall. 21 (1973) 1099-1109. 


\section{Figures}

Fig. 1. EBSD analysis of $80 \%$ cold rolled ODS copper after one-week annealing: a) OIM, b) GBM, c) GOS and 14 months annealing: d) OIM, e) GBM, f) GOS

Fig. 2. Change of misorientation angle distribution during room temperature annealing after a) one week, b) 14 months, and c) comparison of LABs and HABs in as-rolled and annealed conditions

Fig.3. Bright-filed TEM images, a) recrystallized grains inside deformed substructure, b) oxide particle distribution in recrystallized structure

Fig.4. Change of crystallographic texture after long time room temperature annealing, a) Deformed texture at $\varphi_{2}=45^{\circ}$ and b) Recrystallized texture at $\varphi_{2}=0^{\circ}, 45^{\circ}, 65^{\circ}$

Fig. 5. Comparison of mechanical hardness, $\mathrm{HV}_{0.1}(\mathrm{MPa})$ of ODS copper after $80 \%$ cold rolling and 14 months annealing at room temperature 

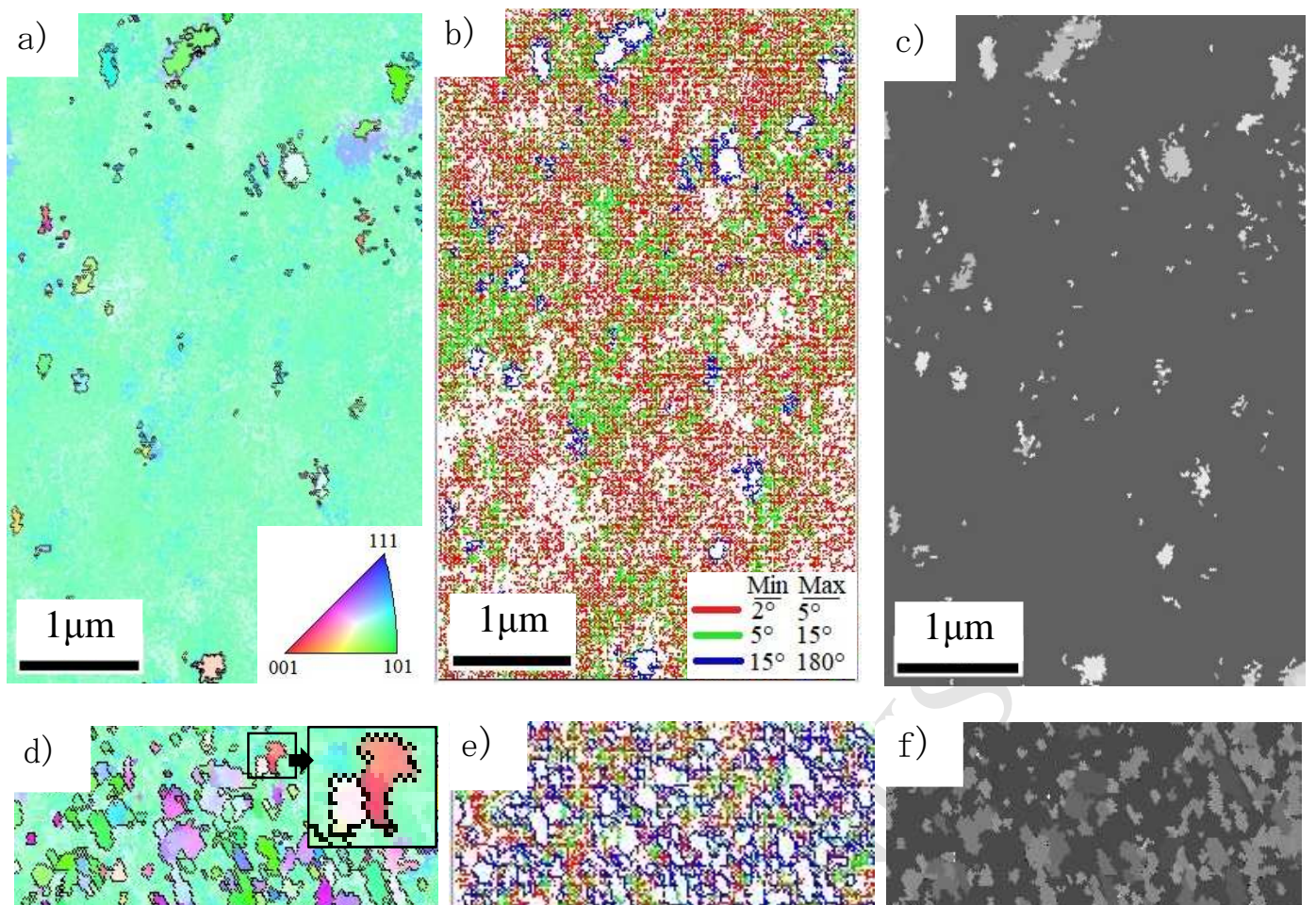

त.

+30 .
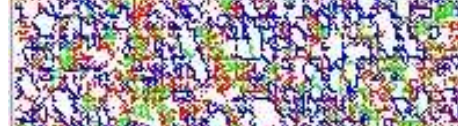

(3) तै iz कर
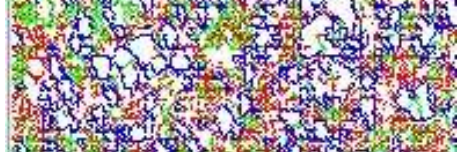

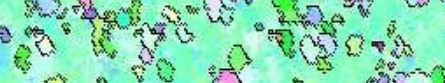
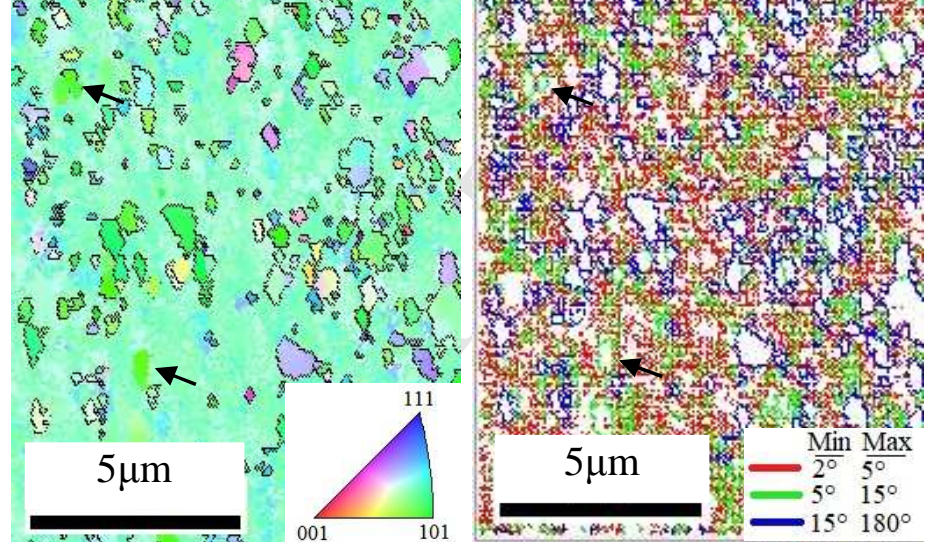

mond

3.
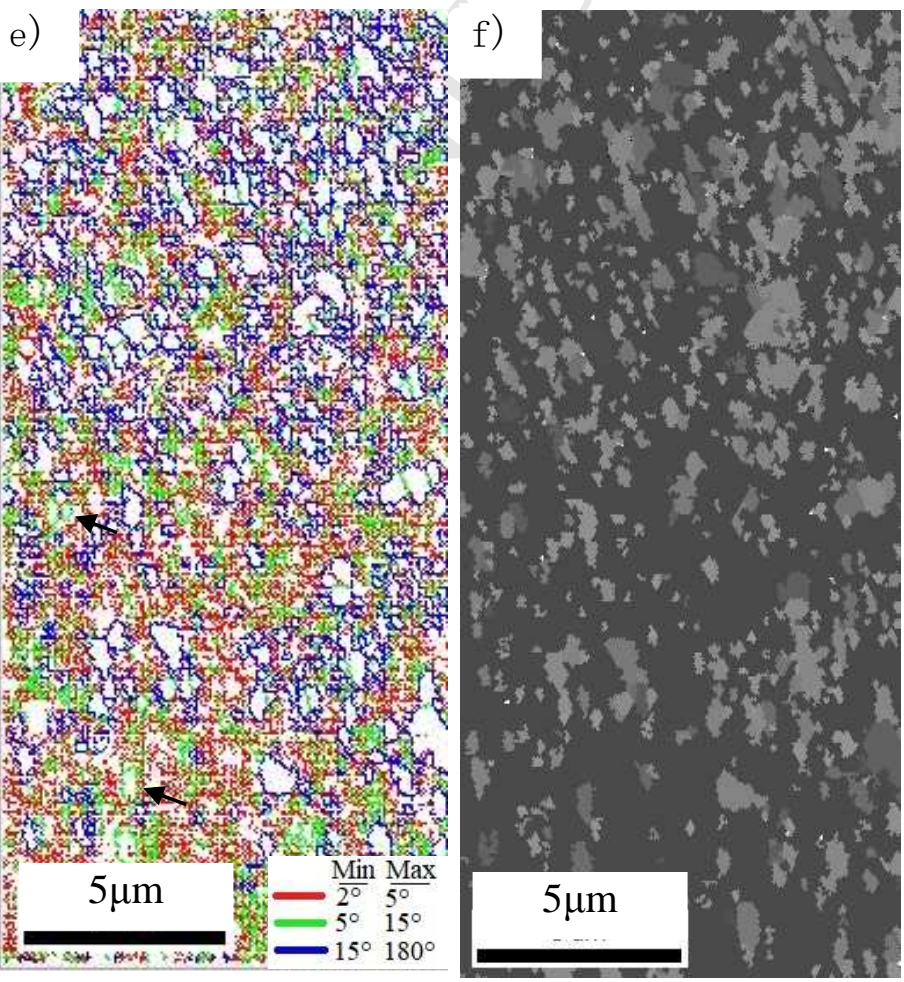

Fig. 1. 

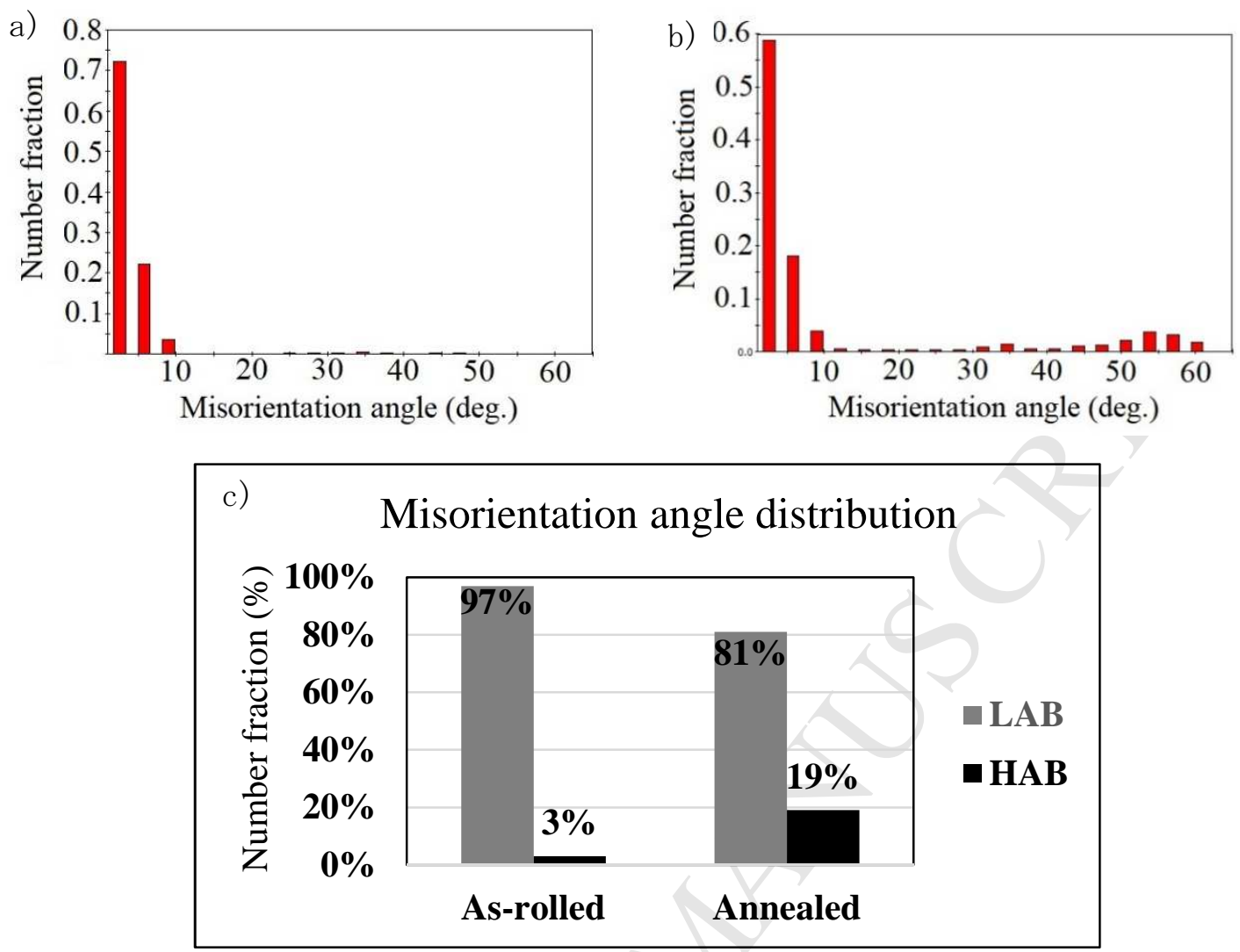

Fig. 2. 


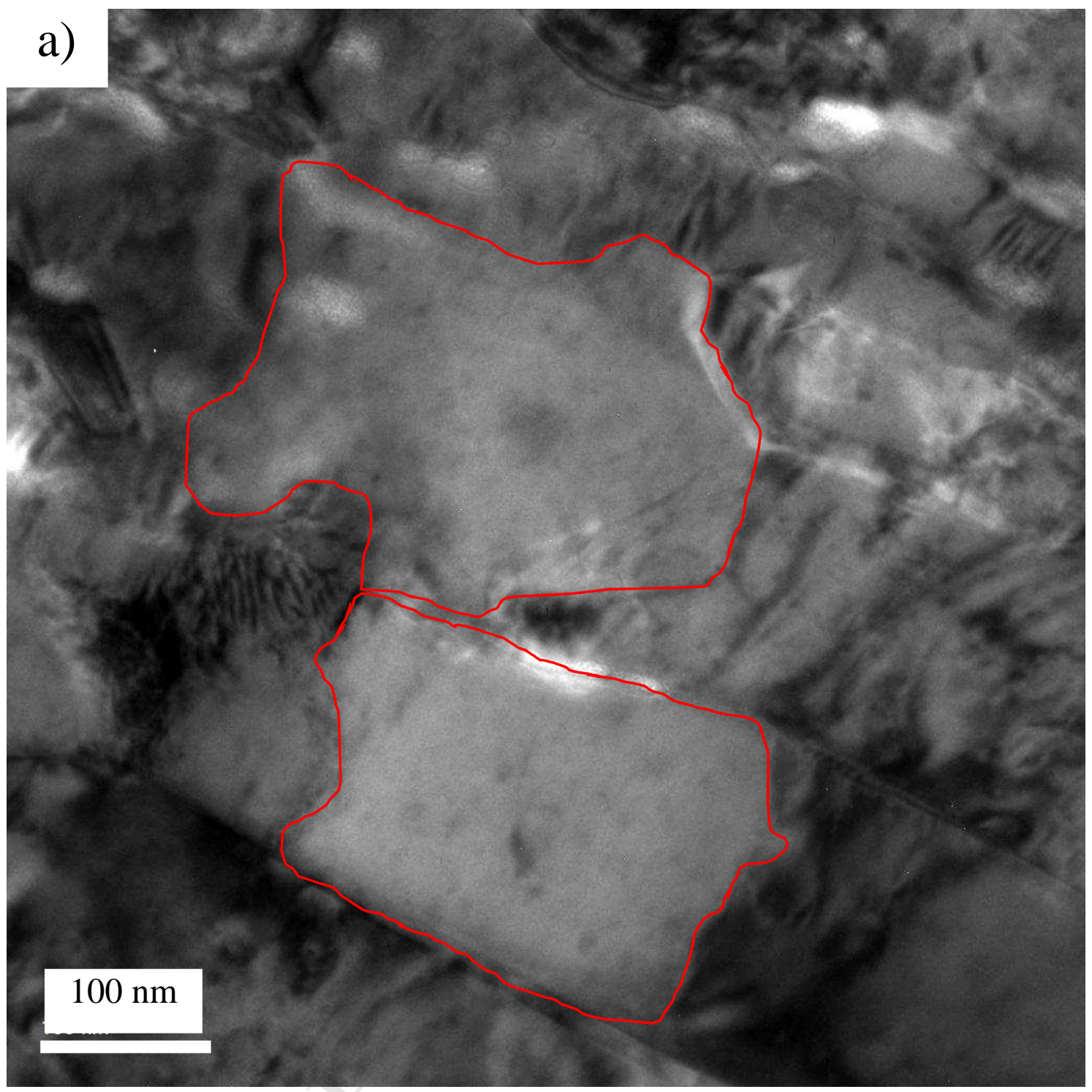

Fig.3 (a) 


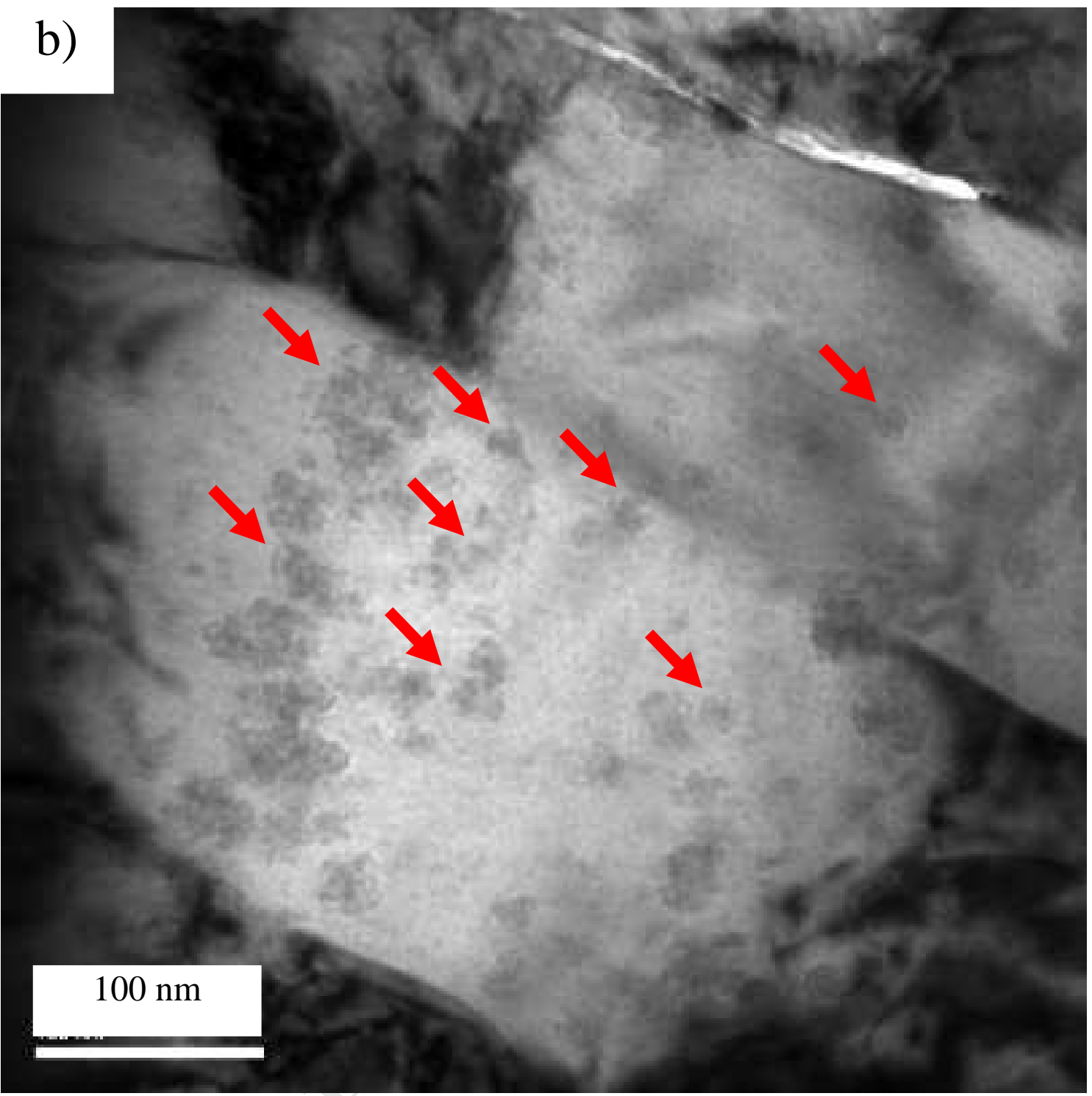

Fig.3 (b) 
b) Recrystallized Texture

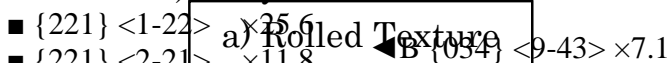

- $\{221\}<2-21>\times 1.81\}<264 \$ 12\}<11>\times 6.8$

$\boldsymbol{\nabla}$ Goss $\{011\}<100>\times 6.6$ P $\{011\}<1-22>\times 3.9$

a)

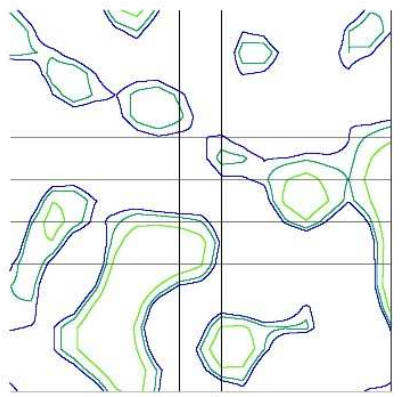

$\varphi_{2}=0^{\circ}$

b)

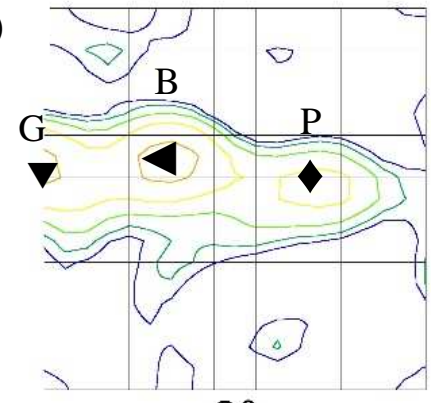

$\varphi 2=0^{\circ}$

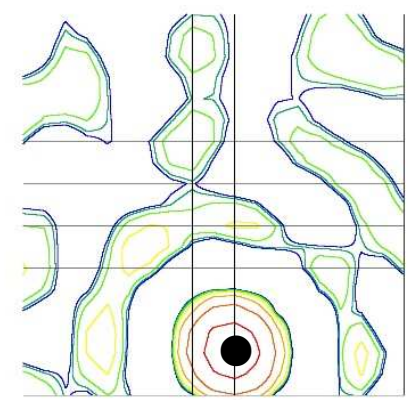

$\varphi 2=45^{\circ}$

$\max =186.030$

$\begin{array}{r}77.861 \\ -32.588 \\ \hline-73.539\end{array}$

-32.588
-13.639

$\begin{array}{r}13.639 \\ -5.709 \\ \hline\end{array}$

$\begin{array}{r}5.389 \\ -1.000 \\ \hline\end{array}$

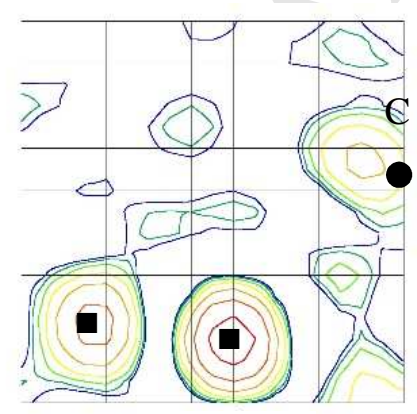

$\varphi_{2}=45^{\circ}$

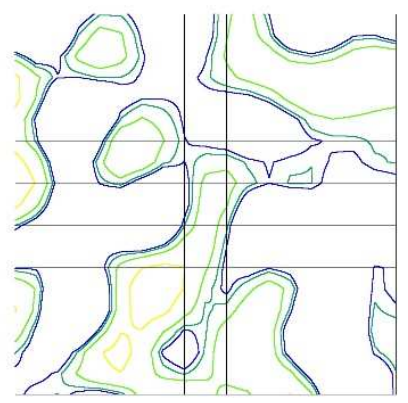

$\varphi_{2}=65^{\circ}$

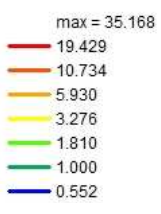

Fig. 4. 


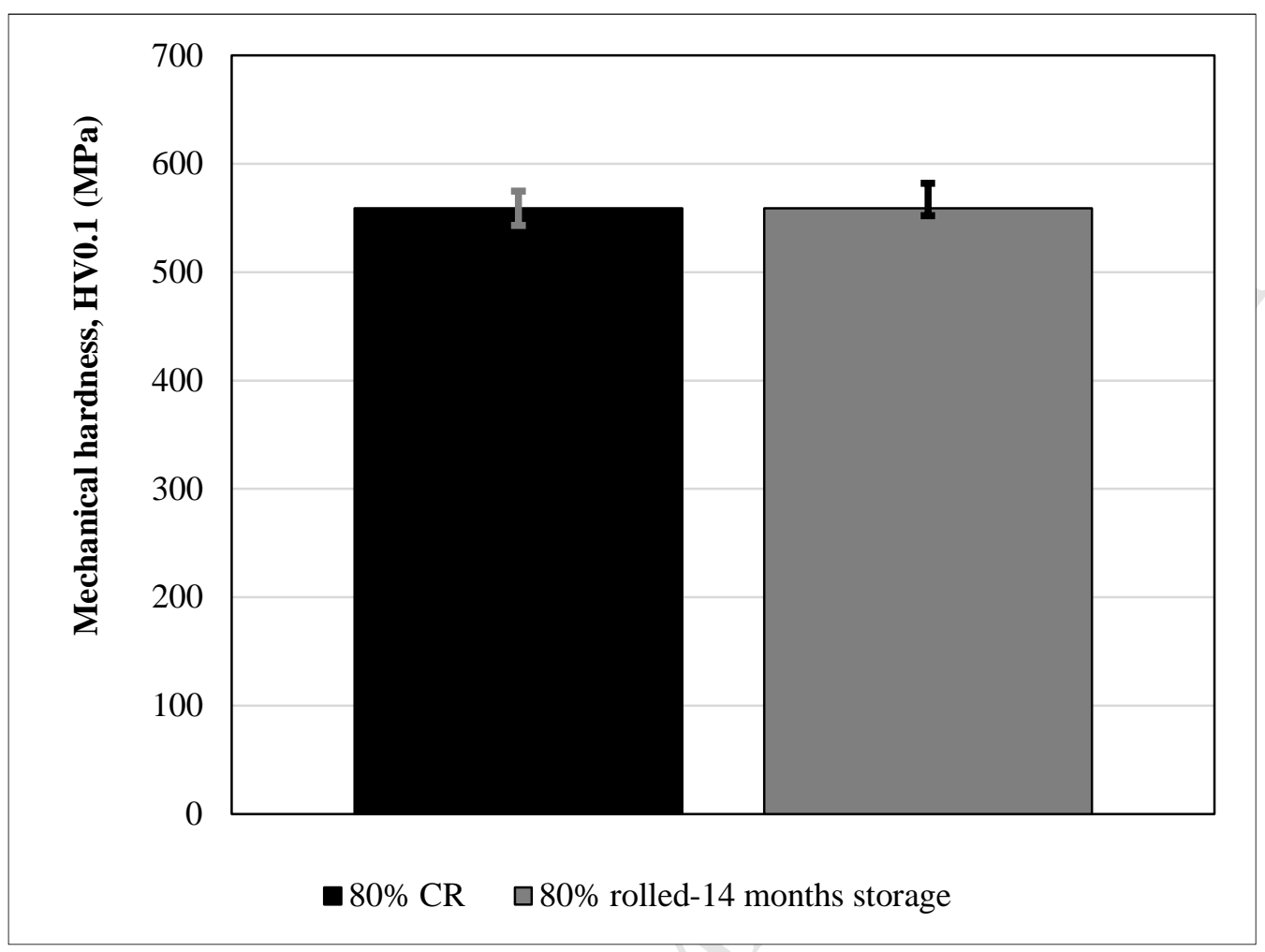

Fig. 5. 


\section{Highlights}

- Recrystallization of ODS copper was studied during room temperature annealing.

- The hardness remained constant by the balance of grain size, oxide particle and strain hardening.

- Transformation of LABs to HABs results in nucleation of recrystallized grains.

- Discontinuous recrystallization happened by significant contribution of static recovery. 